\title{
Constrangimentos Ergonômicos da Manutenção Preventiva de Urnas Eletrônicas de um Tribunal Regional Eleitoral
}

\author{
Ergonomic Constraints of the Preventive Maintenance of Electronic Voting \\ Machines of a Regional Electoral Tribunal
}

\author{
BARROS, Rubenio dos Santos \\ Universidade Federal de Santa Catarina, Mestrando \\ rubeniobarros@hotmail.com
}

FAVARETTO, Alexandre

Universidade Federal de Santa Catarina, Mestrando

alex.alexandrefavaretto@gmail.com

CAVALCANTE, Rodrigo Augusto

Universidade Federal de Santa Catarina, Mestrando

roohdesigner@gmail.com

MERINO, Eugenio Andrés Díaz

Universidade Federal de Santa Catarina, Doutor

eugenio.merino@ufsc.br

\section{RESUMO}

A manutenção preventiva de Urnas Eletrônicas (UE) visa o correto funcionamento das mesmas durante o período eleitoral, sendo uma atividade que envolve milhares de colaboradores. Entretanto, as condições sob as quais a manutenção é realizada pode apresentar aspectos nocivos aos técnicos de manutenção, como um arranjo incongruente, riscos físicos e sobrecarga cognitiva, sendo necessária a detecção de incompatibilidades passíveis de melhoria. Desta forma, este artigo busca o mapeamento e estratificação dos constrangimentos ergonômicos do processo de manutenção de UEs de um tribunal regional eleitoral a partir de uma apreciação ergonômica. A pesquisa se apresenta como aplicada e com objetivo exploratório, sendo realizado um estudo de caso de caráter essencialmente qualitativo. Os resultados indicam que o espaço e o mobiliário não adaptados à atividade de manutenção de UEs expõe os funcionários a um arranjo físico reduzido, a desconfortos físicos como a sobrecarga da região cervical, do tronco e da visão, além de interferir no fluxo de trabalho e na execução das atividades.

Manutenção, urna eletrônica, apreciação ergonômica, sistematização. 


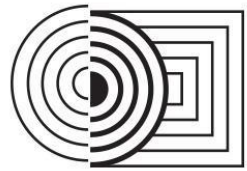

$17^{\circ}$ ERGODESIGN \& USIHC 2019

PUC-Rio, 11 a 13 de dezembro

Rio de Janeiro, RJ, Brasil $17^{\circ}$ Ergodesign - Congresso Internacional de Ergonomia e Usabilidade de Interfaces Humano Tecnológica: Produto, Informações Ambientes Construídos e Transporte

$17^{\circ}$ USIHC - Congresso Internacional de Ergonomia e Usabilidade de Interfaces Humano Computador

\begin{abstract}
The preventive maintenance of Electronic Voting Machines (EVM) seeks their correct functioning during the Brazilian electoral period, being an activity that involves thousands of employees. However, the conditions under which maintenance is performed may present detrimental aspects to maintenance technicians, such as incongruent arrangement, physical risks, and cognitive overload, requiring the detection of incompatibilities for improvement. Thus, this article seeks to map and stratify the ergonomic constraints of the electronic voting machines maintenance process of a regional electoral Tribunal via an ergonomic appreciation. The research presents itself as applied, with exploratory objective, being carried out a case study of essentially qualitative character. The results indicate that the use of space and furniture not adapted to the maintenance activity of EVMs exposes employees to a reduced physical arrangement, physical discomforts such as overload of the cervical region, trunk, and vision, as well as interfering with workflow and the execution of activities.
\end{abstract}

Maintenance, electronic voting machine, ergonomic appreciation, systematization.

\title{
1. INTRODUÇÃO
}

A garantia da realização bem-sucedida do processo eleitoral brasileiro requer a articulação de diversos atores, desde o cuidado inicial quanto ao correto funcionamento dos equipamentos utilizados antes, durante e após as eleições, até a distribuição nas diferentes localidades, sob as mais diversas condições de infraestrutura e logística, para que seja possível a garantia do direito ao voto (TSE, 2016; JUSTIÇA ELEITORAL, 2012).

Um desses equipamentos que é central na viabilização das eleições é a Urna Eletrônica (UE) (Figura 1), que de acordo com o Tribunal Superior Eleitoral - TSE (2010), é um microcomputador de uso específico para realização dos processos eleitorais, que conta com recursos de segurança, como o embaralhamento de dados, garantindo o sigilo do voto e a confiabilidade do processo de votação.

Figura 1: exemplo de Urna Eletrônica. Fonte: TSE (2018a).

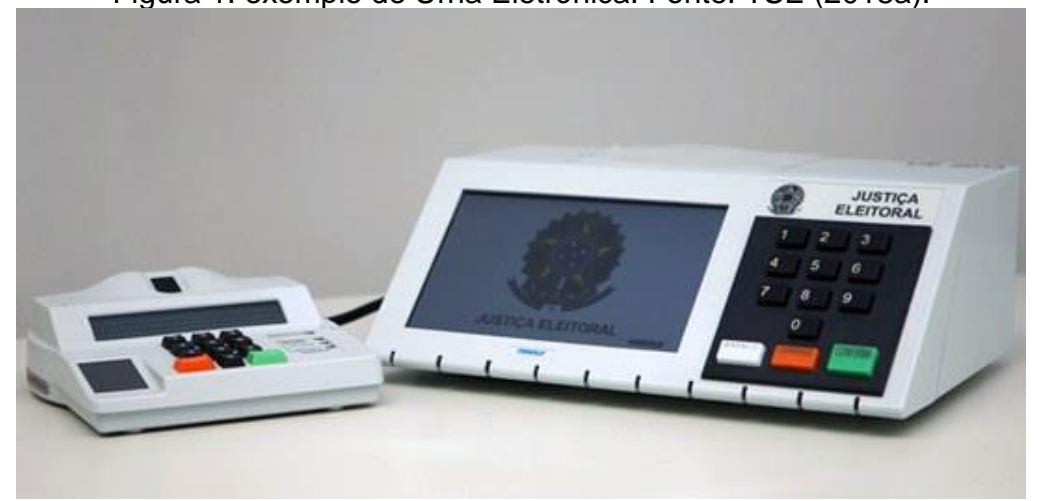

A UE é composta periféricos, mecanismos internos e acessórios, como bateria interna, impressora e cartões de memória, que precisam estar em correto funcionamento quando em período eleitoral para que não ocorram atrasos, avarias no equipamento, ou que surjam interferências indesejadas relacionadas ao funcionamento das UEs nas eleições.

Nesse sentido, o TSE por meio de suas repartições regionais denominadas Tribunais Regionais Eleitorais (TREs), realiza a checagem e manutenção das UEs. Nas atividades da manutenção, que podem ser do tipo preventiva ou corretiva, são verificados elementos essenciais para o funcionamento das UEs, como carga de baterias, detecção de defeitos, limpeza, testes, 


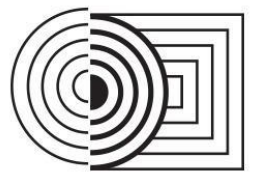

\section{$17^{\circ}$ ERGODESIGN \& USIHC 2019 \\ PUC-Rio, 11 a 13 de dezembro \\ Rio de Janeiro, RJ, Brasil}

$17^{\circ}$ Ergodesign - Congresso Internacional de Ergonomia e Usabilidade

de Interfaces Humano Tecnológica: Produto, Informações Ambientes Construídos e Transporte

$17^{\circ}$ USIHC - Congresso Internacional de Ergonomia e Usabilidade

de Interfaces Humano Computador

impressão de relatórios, retestes, reposição de componentes, etc. (JUSTIÇA ELEITORAL, 2010).

A Manutenção Preventiva é realizada de forma periódica para analisar o funcionamento das urnas e detectar possíveis problemas. Essa manutenção é realizada por meio de um software fornecido pelo TSE, denominado Sistema de Teste Exaustivo (STE), que é instalado nas Memórias de Resultado (MRs - pen drives projetados para uso nas UEs), que rodam o software na urna para verificar as condições de funcionamento. Já a Manutenção Corretiva é realizada para solucionar os problemas identificados durante a manutenção preventiva, e pode ser realizada em paralelo à manutenção preventiva (JUSTIÇA ELEITORAL, 2012).

Devido ao contingente de urnas existentes no Brasil (segundo o TSE, foram necessárias 454.493 urnas nas eleições de 2018), aos diversos componentes que precisam ser analisados, a periodicidade do processo de manutenção e pelo próprio rigor exigido, é necessário o apoio de milhares de colaboradores, que executam os processos de manutenção durante todo o ano. Para as eleições de 2014, o TSE realizou licitação para contratação e treinamento em manutenção de UEs de 14 mil profissionais, a um custo de $\mathrm{R} \$ 129$ milhões. Esse número de profissionais não leva em conta os demais funcionários dos próprios TREs, que auxiliam direta e indiretamente na manutenção (TSE, 2012, 2017, 2018b).

Assim, é válida a averiguação das condições de trabalho em que são feitas as atividades de manutenção, observando como o fator humano está inserido nesse sistema e quais os impactos que as condições de trabalho podem gerar na saúde e na produtividade. Para tal, é necessária a consideração de princípios ergonômicos que possibilitem uma análise sistemática. A Ergonomia fornece um acervo de conhecimentos, princípios gerais, medidas básicas das capacidades humanas e técnicas para serem aplicadas no projeto e funcionamento das máquinas, sistema e ambientes de trabalho (IIDA; GUIMARÃES, 2016).

Segundo Dul e Weerdmeester (2012), a Ergonomia é imprescindível, pois quando aplicada na ambiência, é capaz de reunir informações, além de analisar e integrar conhecimentos importantes de diferentes áreas, como a Percepção Ambiental, que é a interação entre o homem e o ambiente onde será desenvolvida uma atividade; a Antropometria, que estuda as dimensões e proporções do corpo humano, sendo utilizada para auxiliar nas recomendações sobre postura e movimento; e o Conforto Ambiental, que é o estudo dos fatores ambientais ruído, temperatura, luz, etc. - para favorecer o conforto acústico, térmico, cromático, etc. Desta forma, além da segurança do trabalhador envolvido, o que é primordial, a Ergonomia pode trazer impactos significativos para o desempenho do sistema que envolve a manutenção preventiva de urnas, como a melhora na eficiência, na confiabilidade e na qualidade das operações desempenhadas (IIDA; GUIMARÃES, 2016).

Assim, este artigo busca o mapeamento e a estratificação dos constrangimentos ergonômicos da manutenção de urnas eletrônicas de um tribunal regional eleitoral brasileiro a partir de uma apreciação ergonômica, de modo a identificar os riscos contidos no sistema. Segundo Moraes e Mont'Alvão (2009), a apreciação é uma fase exploratória que compreende a sistematização do sistema homem-tarefa-máquina, junto com o mapeamento e a delimitação dos problemas ergonômicos da empresa, culminando na modelagem e na apresentação das disfunções do sistema.

Para lida e Guimarães (2016), a melhoria de sistemas já elaborados e implementados, como no caso do setor de manutenção preventiva de urnas, parte da análise das condições existentes. Os autores complementam que a aplicação sistemática da Ergonomia é feita identificando onde ocorrem problemas ergonômicos, que podem ser reconhecidos por certos sintomas como alto índice de erros, acidentes, doenças, absenteísmo e rotatividade dos trabalhadores. Por trás dessas evidências podem estar ocorrendo inadaptações das máquinas, deficiências ambientais 


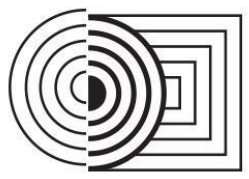

$17^{\circ}$ ERGODESIGN \& USIHC 2019

PUC-Rio, 11 a 13 de dezembro

Rio de Janeiro, RJ, Brasil

$17^{\circ}$ Ergodesign - Congresso Internacional de Ergonomia e Usabilidade de Interfaces Humano Tecnológica: Produto, Informações Ambientes Construídos e Transporte

$17^{\circ}$ USIHC - Congresso Internacional de Ergonomia e Usabilidade de Interfaces Humano Computador

e falhas na organização do trabalho, se mostrando assim como oportunidades de estudos.

\section{PROCEDIMENTOS METODOLÓGICOS}

De acordo com Prodanov e Freitas (2013), esta pesquisa pode ser caracterizada como de natureza aplicada, abordagem qualitativa, objetivo exploratório, se utilizando como procedimento técnico de um estudo de caso.

A pesquisa envolve levantamento em campo, análise e tratamento dos dados coletados, culminando na estratificação dos constrangimentos ergonômicos. Em todas as etapas foram tomados cuidados éticos quanto a preservação do anonimato e a confidencialidade dos dados obtidos a partir das entrevistas e observações junto aos sujeitos de pesquisa.

\subsection{Materiais e métodos}

\subsubsection{Levantamento de dados}

O estudo de caso foi realizado em um Tribunal Regional Eleitoral, mais especificamente no setor de administração e manutenção de UEs. Foram realizadas três visitas de campo para levantamento de dados, sendo utilizadas as ferramentas de observação

assistemática e sistemática direta e indireta, com o registro das observações diretas realizadas por anotações em caderno de campo e gravações de áudio, enquanto que as observações indiretas registradas por meio fotografias e vídeo (MORAES; MONT'ALVÃO, 2009). Foram feitas ainda entrevistas abertas, não diretivas e semiestruturadas com o chefe do setor, o preposto (técnico responsável pelos demais técnicos) e com os técnicos de manutenção preventiva e corretiva de urnas, de modo a compreender o fluxo e as atividades executadas. A seguir, a Figura 2 apresenta a síntese das visitas de campo e as ferramentas utilizadas.

Figura 2: visitas de campo e as ferramentas utilizadas. Fonte: autores.

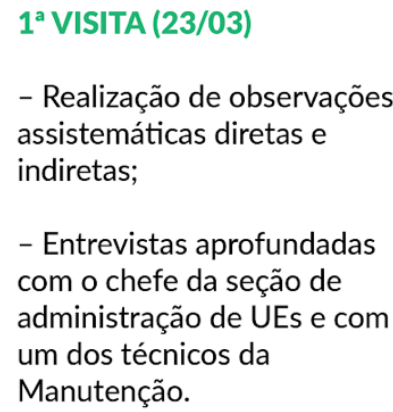

$1^{\text {a }} \operatorname{VISITA~(23/03)~}$

- Realização de observações assistemáticas diretas e com o chefe da seção de um dos técnicos da Manutenção.

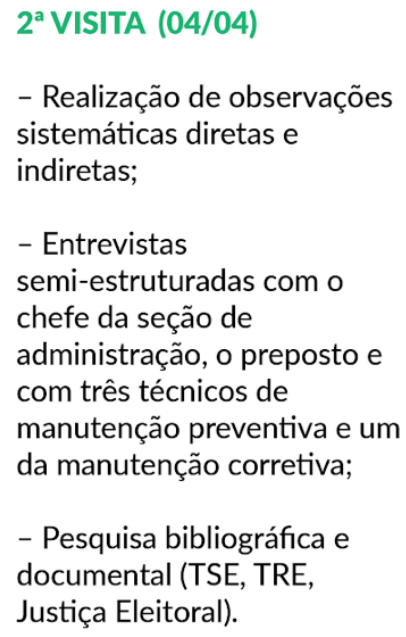

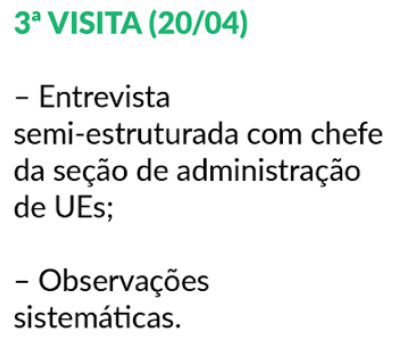

Junto às atividades dentro do Tribunal, foram realizadas pesquisas bibliográfica e documental acerca dos processos de manutenção de urnas, das ferramentas e mobiliários utilizados, e das normas da Justiça Eleitoral para tal atividade (TSE, 2010, JUSTIÇA ELEITORAL, 2012). 
$17^{\circ}$ ERGODESIGN \& USIHC 2019

PUC-Rio, 11 a 13 de dezembro Rio de Janeiro, RJ, Brasil $17^{\circ}$ Ergodesign - Congresso Internacional de Ergonomia e Usabilidade de Interfaces Humano Tecnológica: Produto, Informações Ambientes Construídos e Transporte

$17^{\circ}$ USIHC - Congresso Internacional de Ergonomia e Usabilidade de Interfaces Humano Computador

\subsubsection{Análise e tratamento dos dados}

Para análise do conteúdo levantado, é válida a elaboração de modelos e representações do funcionamento do sistema e de suas operações, de modo a facilitar o estudo e a compreensão das características, das atividades e das particularidades encontradas (MORAES; MONT'ALVÃO, 2009).

De modo a representar visualmente as principais variáveis envolvidas na manutenção de UEs, inicialmente foi elaborado um mapa mental. O mapa mental é uma ferramenta não linear de representação para o gerenciamento de informações, se utilizando de palavras, símbolos, cores e desenhos para a construção da representação (HERMANN; BOVO, 2005; PAZMINO, 2015).

Em seguida, foram construídas as modelagens para a sistematização do sistema homemtarefa-máquina, de Moraes e Mont'Alvão (2009). A seguir, são descritas as representações desenvolvidas.

1. Caracterização e Posição Serial do Sistema: compreende a definição da meta/missão, o ambiente de execução das tarefas, os requisitos, as restrições, os resultados despropositados, as entradas e saídas, explicitando a relação entre esses elementos e seus respectivos papéis no funcionamento do sistema.

2. Ordenação Hierárquica do Sistema: posiciona o sistema-alvo de acordo com sua contingência ou inclusão em outros sistemas hierarquicamente superiores, além de explicitar os sistemas contidos no sistema-alvo.

3. Modelagem Comunicacional do Sistema: apresenta a transmissão de informações, indicando os subsistemas humanos envolvidos (sentidos humanos) na tomada de informação/percepção, os subsistemas humanos de resposta/regulação (ações realizadas), os subsistemas da máquina que fornecem informações para serem processadas pelo homem, e os subsistemas da máquina que recebem as ações do homem.

4. Fluxograma Funcional Ação-Decisão: apresenta sequencialmente as funções/operações/atividades que podem ser realizadas em série, simultâneas e alternativamente, além das decisões implicáveis nesses processos.

\subsubsection{Estratificação dos problemas}

Após o mapeamento, os principais constrangimentos ergonômicos identificados foram estratificados de acordo com os domínios de especialização da Ergonomia, para em seguida serem confrontados com a literatura técnico-científica e as Normas Regulamentadoras (NRs) pertinentes, visando identificar os impactos e os riscos para o sistema e para os indivíduos.

\section{RESULTADOS E DISCUSSÕES}

As ações desenvolvidas no setor de administração de urnas do Tribunal analisado têm como objetivo certificar que as urnas estejam prontas e em adequado funcionamento para as próximas eleições. As operações são realizadas em instalações (galpão de armazenamento, Figura 3) alugadas, sendo um ambiente que não foi projetado com foco na manutenção de urnas e que precisou de adaptações para sua utilização. No galpão foram feitas divisões para acomodar a parte administrativa, um refeitório com banheiro e um pequeno depósito para os funcionários. Na parte administrativa trabalham 3 servidores do Tribunal, enquanto que os demais funcionários são terceirizados. 


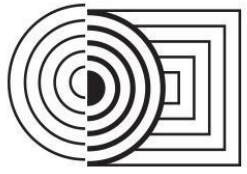

$17^{\circ}$ ERGODESIGN \& USIHC 2019

PUC-Rio, 11 a 13 de dezembro

Rio de Janeiro, RJ, Brasil $17^{\circ}$ Ergodesign - Congresso Internacional de Ergonomia e Usabilidade de Interfaces Humano Tecnológica: Produto, Informações Ambientes Construídos e Transporte

$17^{\circ}$ USIHC - Congresso Internacional de Ergonomia e Usabilidade de Interfaces Humano Computador

Figura 3: instalações do TRE. Fonte: autores.
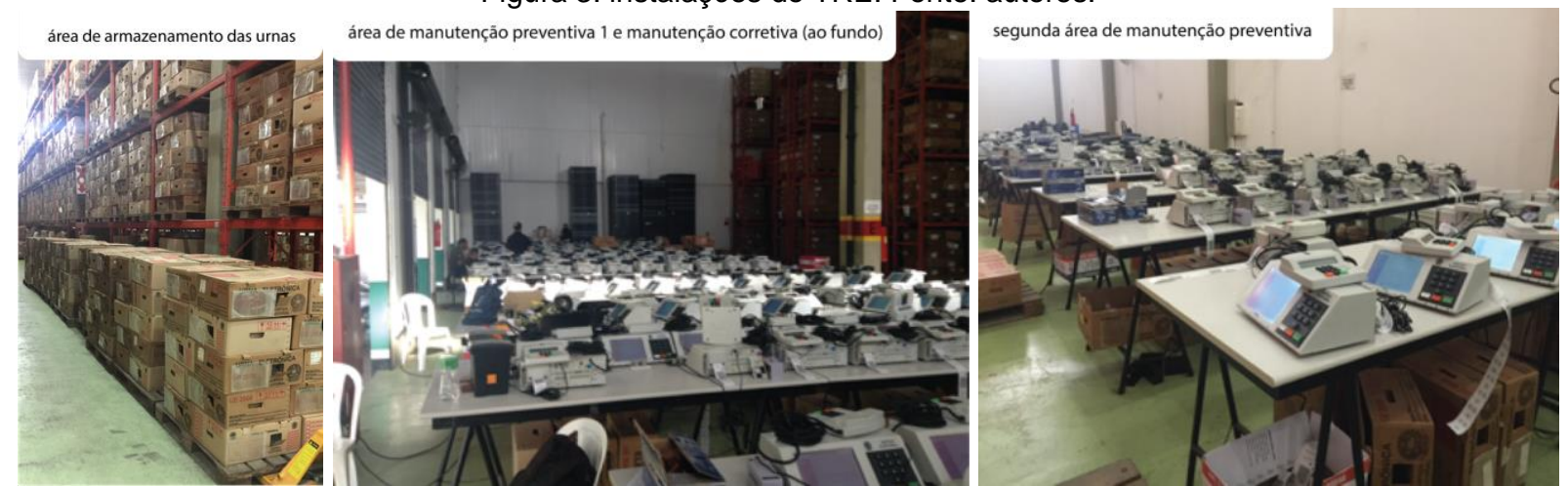

Acerca da capacidade e abrangência das atividades realizadas no setor, é feito o acondicionamento e manutenção de aproximadamente 19.000 urnas, que durante as eleições são distribuídas para 98 Cartórios Eleitorais e para 3.780 locais de votação dentro do estado ao qual o TRE atende, sendo 16.220 urnas utilizadas na eleição e 2.780 mantidas como reservas. Sobre a manutenção, ao longo do ano, cada uma das 19.000 urnas passa por 3 ciclos de manutenção preventiva. Os técnicos realizam a manutenção de aproximadamente 300 urnas por dia, sendo que cada técnico é responsável por uma média diária de 30 a 35 urnas. 0 período integral de testes começa num dia e termina no outro. A manutenção é realizada por 10 técnicos terceirizados, que trabalham 6 horas diárias, das $13 \mathrm{~h}$ às $19 \mathrm{~h}$. O nível de instrução requerido para o cargo é o $2^{\circ}$ Grau completo. Em média, esses funcionários permanecem no posto 2 anos e, ao serem contratados novos técnicos, o treinamento acerca das atividades é realizado pelo funcionário com mais tempo de experiência no setor.

\subsection{Detalhamento do processo de manutenção}

A manutenção se inicia com a recuperação das embalagens que acondicionam as urnas a serem testadas, que ficam armazenadas em estruturas metálicas (porta pallets) distribuídas no galpão (Figura 3). Cada embalagem com UE pesa aproximadamente $10 \mathrm{~kg}$. A remoção dos porta pallets é feita com uma empilhadeira e, após a recuperação das embalagens, são formados grupos de 20 a 22 urnas sobrepostas sobre os pallets que serão distribuídos entre os funcionários da manutenção. A interação do técnico de manutenção preventiva com a urna se inicia a partir do contato com esses grupos de UEs que são distribuídos em frente às estações de trabalho.

Cada técnico realiza suas atividades em duas estações de trabalho: uma contendo um grupo de 3 mesas, e outra, que fica mais afastada no fundo do galpão, com 2 mesas. Essa divisão espacial é resultante da falta de espaço na principal área utilizada para manutenção. Após a desembalagem das urnas sobre as mesas é iniciada as atividades de manutenção. Ao fim do processo, caso não apresentem problemas, cada urna é novamente embalada e transportada manualmente até o pallet para retornarem ao local de armazenamento.

Acerca das mesas utilizadas na manutenção, cada uma possui 2 metros de largura para 1 metro de comprimento, e no centro contam com instalações elétricas e tomadas que permitem a conexão entre as mesas para fornecer energia às urnas. Vale ressaltar que esse mobiliário não apresenta ajustes da altura.

Os testes que são executados durante a manutenção fazem a checagem minuciosa dos componentes, sendo a grande maioria desses componentes e do sistema verificados 
automaticamente. Entretanto, em determinados momentos o teste requer a interação com os técnicos (Teste do Operador), para a checagem do funcionamento e confirmação de feedback dos componentes da UE, como teclado, monitor, indicadores sonoros, impressora, dentre outros.

Sobre a atividade exercida, observa-se que não há uma padronização quanto ao posicionamento das urnas sobre as mesas. Cada técnico adota o posicionamento da urna de acordo com suas preferências (melhor visualização, maior número de urnas por mesas, etc.). Quando é detectado algum problema/falha, primeiramente o terminal do mesário é posicionado verticalmente sobre a urna (Figura 4). Em seguida, é feito um relatório manual detalhando o problema, para que a urna seja realocada para o lote de urnas defeituosas e então aguarde chamado para realização de manutenção corretiva.

Figura 4: indicação de urna defeituosa. Fonte: autores

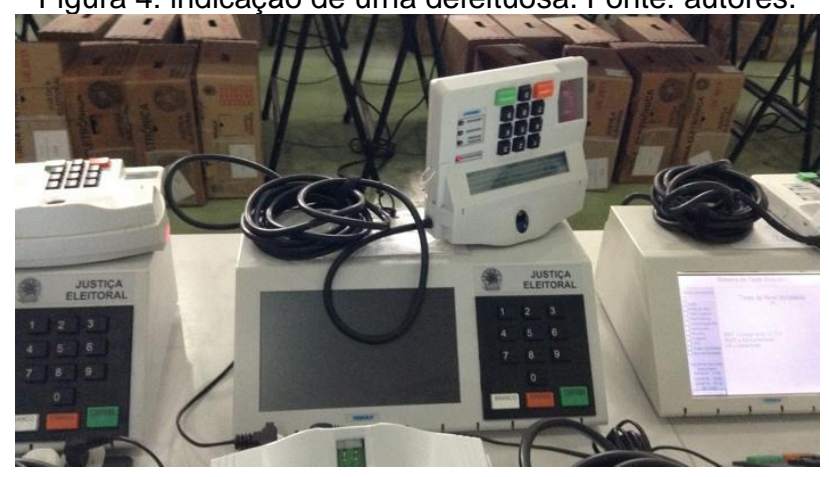

O trabalho realizado na manutenção corretiva é feito por um técnico contratado diretamente pelo Tribunal Superior Eleitoral - TSE para fazer a manutenção inicial e, caso não seja possível solucionar os problemas, as urnas são encaminhadas, em lotes de no máximo 15 urnas, para uma central de manutenção. Mesmo após sofrerem a correção nessa central de manutenção, as urnas passam por nova rodada de testes para confirmação da elucidação dos problemas. Esse procedimento é chamado de Reteste e também é feito pelos técnicos de manutenção preventiva.

Acerca das especificidades da tarefa de manutenção preventiva, foi possível observar que os técnicos fazem o teste do operador em mais de uma urna ao mesmo tempo, e que o trabalho pode ser caracterizado como de constante exigência de atenção para diversos elementos (observação do funcionamento das urnas, acompanhamento dos diferentes estágios de desenvolvimento dos testes, etc.). Segundo informações coletadas por meio das entrevistas com os funcionários, foi relatado que o período de maior demanda é quando as urnas retornam após as eleições, pois além da manutenção também é feita a limpeza e a remoção dos lacres das urnas.

Percebe-se a execução de tarefas simultâneas e a constante tomada de decisões, como no caso da digitação das teclas para prosseguimento das etapas dos testes e para os feedbacks durante o Teste do Operador, além da alta repetitividade de movimentos.

Acerca dos pontos positivos observados, destacam-se: a boa comunicação entre os técnicos e os superiores; a manutenção regular dos equipamentos; a atenção quanto a realização das pausas pelos funcionários, além da disponibilização de cadeiras para descanso durante a execução dos testes que não requerem a interação constante com a urna.

De modo geral, como apresentado no mapa mental (Figura 5), a manutenção preventiva envolve a carga de baterias, a limpeza da superfície externa das urnas e seus componentes, 
além da substituição de componentes que podem ter sido perdidos, avariados ou tenham se esgotado (lacres, parafusos, bobina da impressora, etc.). Há a realização dos testes para a detecção dos problemas, o controle da verificação das urnas (relatórios e o registro do patrimônio, que é o código de barras da urna), além do correto acondicionamento das urnas nas embalagens.

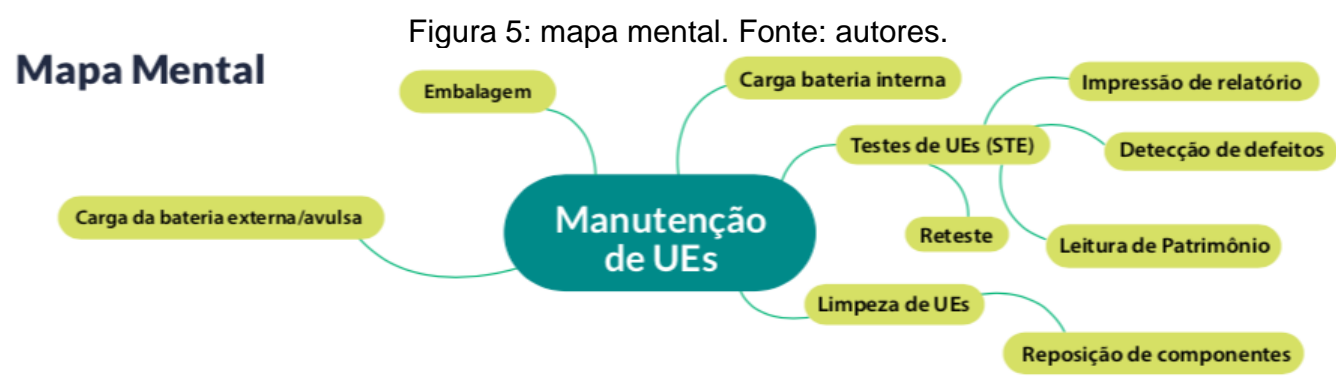

\subsection{Sistematização do processo de manutenção}

Como mostrado na Figura 6, que representa a Ordenação Hierárquica do Sistema, a manutenção preventiva de urnas está inserida dentro do ecossistema do TSE, que rege o funcionamento dos TREs. Dentro do TSE, tem-se a Coordenadoria de Eleições, que também atua na administração do processo eleitoral dentro dos estados e municípios. Por sua vez, a Coordenadoria de Eleições incorpora o setor administrativo de manutenção, tendo o auxílio de funcionários terceirizados para a realização das atividades do setor. Dentre os funcionários, há o preposto, que é aquele encarregado pela administração das ações executadas pelos demais técnicos da manutenção, e o principal elo de comunicação com os gestores do sistema imediatamente superior (TSE, 2019).

Figura 6: Ordenação Hierárquica do Sistema. Fonte: autores.

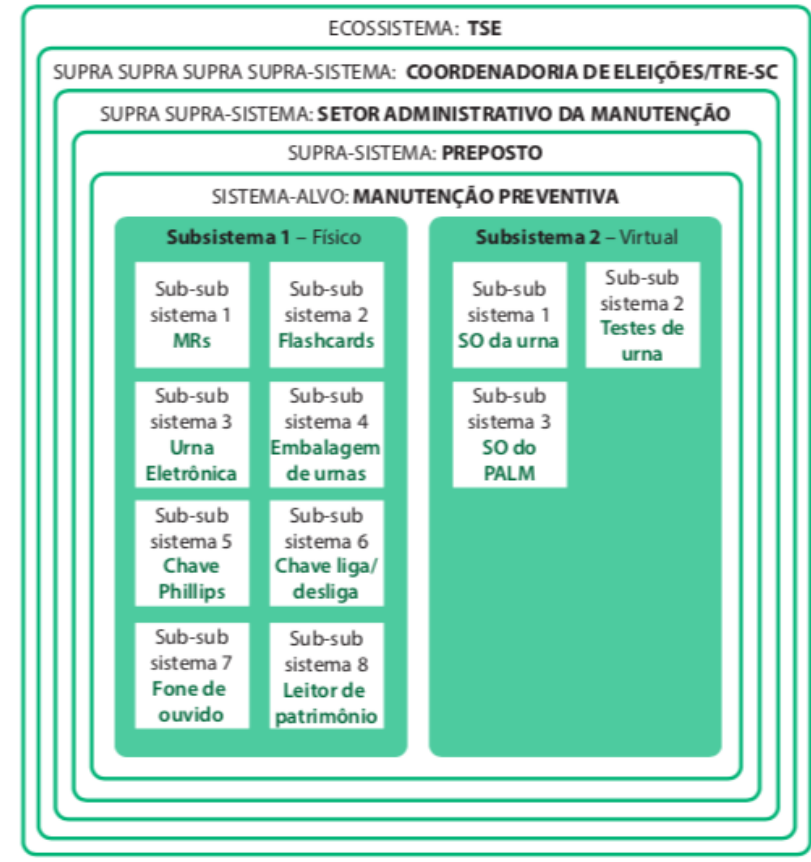




\section{$17^{\circ}$ ERGODESIGN} \& USIHC 2019

PUC-Rio, 11 a 13 de dezembro

Rio de Janeiro, RJ, Brasil $17^{\circ}$ Ergodesign - Congresso Internacional de Ergonomia e Usabilidade de Interfaces Humano Tecnológica: Produto, Informações Ambientes Construídos e Transporte

$17^{\circ}$ USIHC - Congresso Internacional de Ergonomia e Usabilidade

de Interfaces Humano Computador

A Modelagem Comunicacional (Figura 7) apresenta as fontes de informação a serem processadas pelos técnicos de manutenção, sendo muitas dessas fontes os próprios comandos a serem ativados a partir dos acionamentos realizados para execução das respostas humanas. Um exemplo que pode ser citado, é a conexão das MRs e a urna para execução dos testes. As MRs e a urna fornecem informações pelo canal de transmissão visual (sistema humano envolvido), os quais a partir do processamento cognitivo utilizam os olhos para identificarem (acionamentos) as portas USB para conexão, e com os braços e mãos conectar (acionamentos) ambos dispositivos (comandos ativados).

Figura 7: Modelagem Comunicacional do Sistema. Fonte: autores.

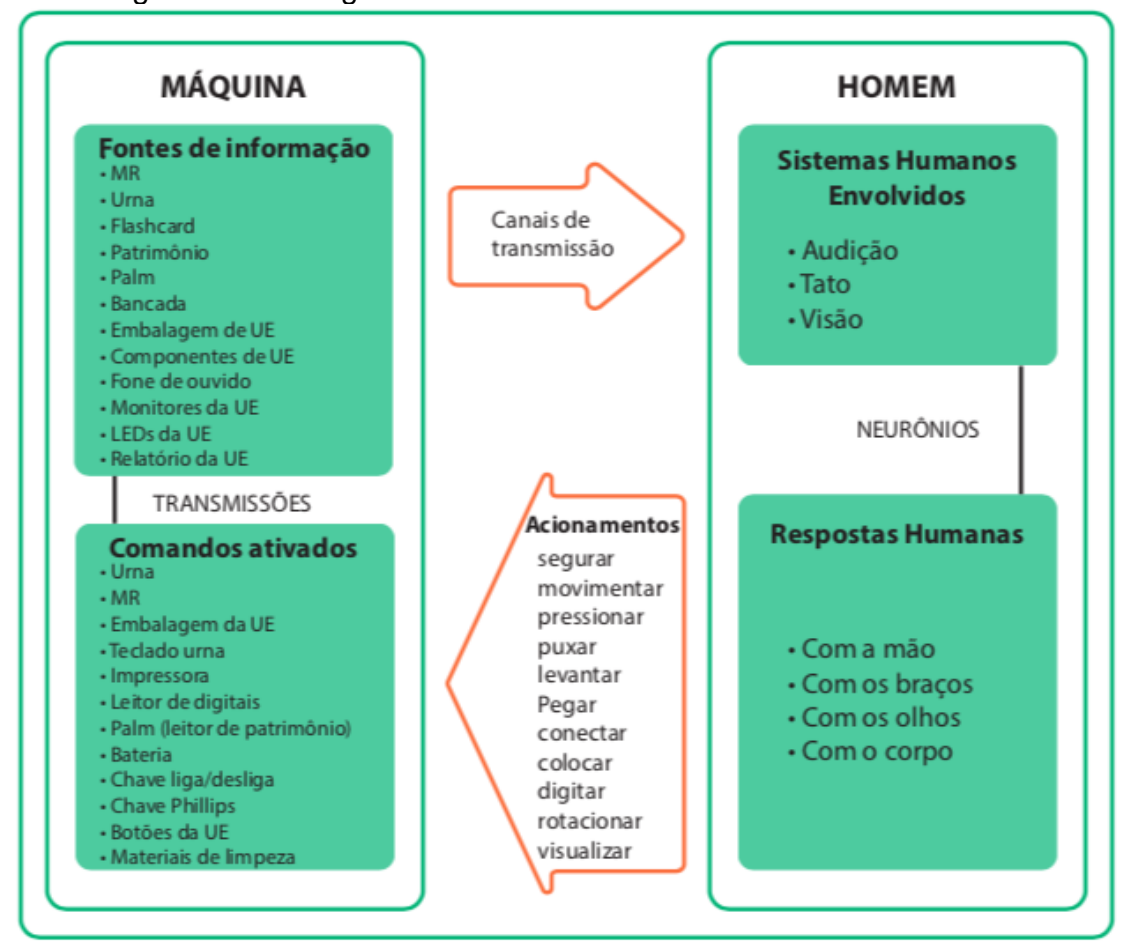

A Figura 8 apresenta a Caracterização e Posição Serial do Sistema, contendo a sintetização dos principais elementos considerados pelo sistema-alvo (manutenção preventiva) durante a execução das atividades, sendo possível construir um fluxo de entrada e saída das demandas. Como exemplo, pode ser descrito como sistema alimentador a Coordenadoria de Eleições, que solicita a manutenção de urnas (entrada) para o sistema-alvo (manutenção preventiva), que a partir das suas ações geram como saídas a execução dos testes, a identificação das urnas defeituosas, os relatórios dos testes, dentre outras saídas, que serão encaminhadas para a Coordenadoria de Eleições (sistema ulterior). 
Figura 8: Caracterização e Posição Serial do Sistema. Fonte: autores.

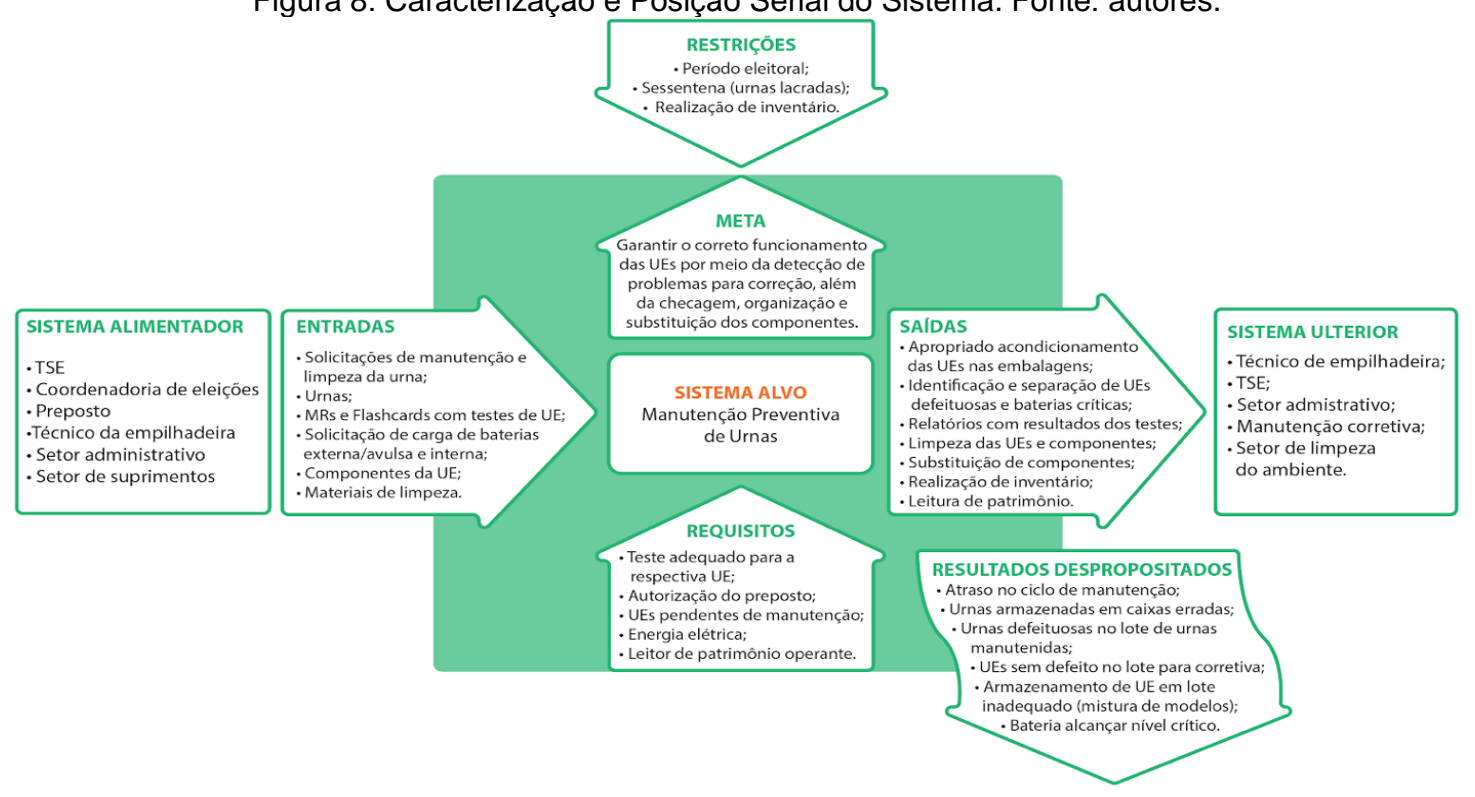

O Fluxograma Funcional Ação-Decisão (Figura 9) sintetiza as principais ações da manutenção preventiva e do Reteste após a manutenção corretiva, além das ações de controle realizadas.

Figura 9: fluxograma Funcional Ação-Decisão. Fonte: autores.

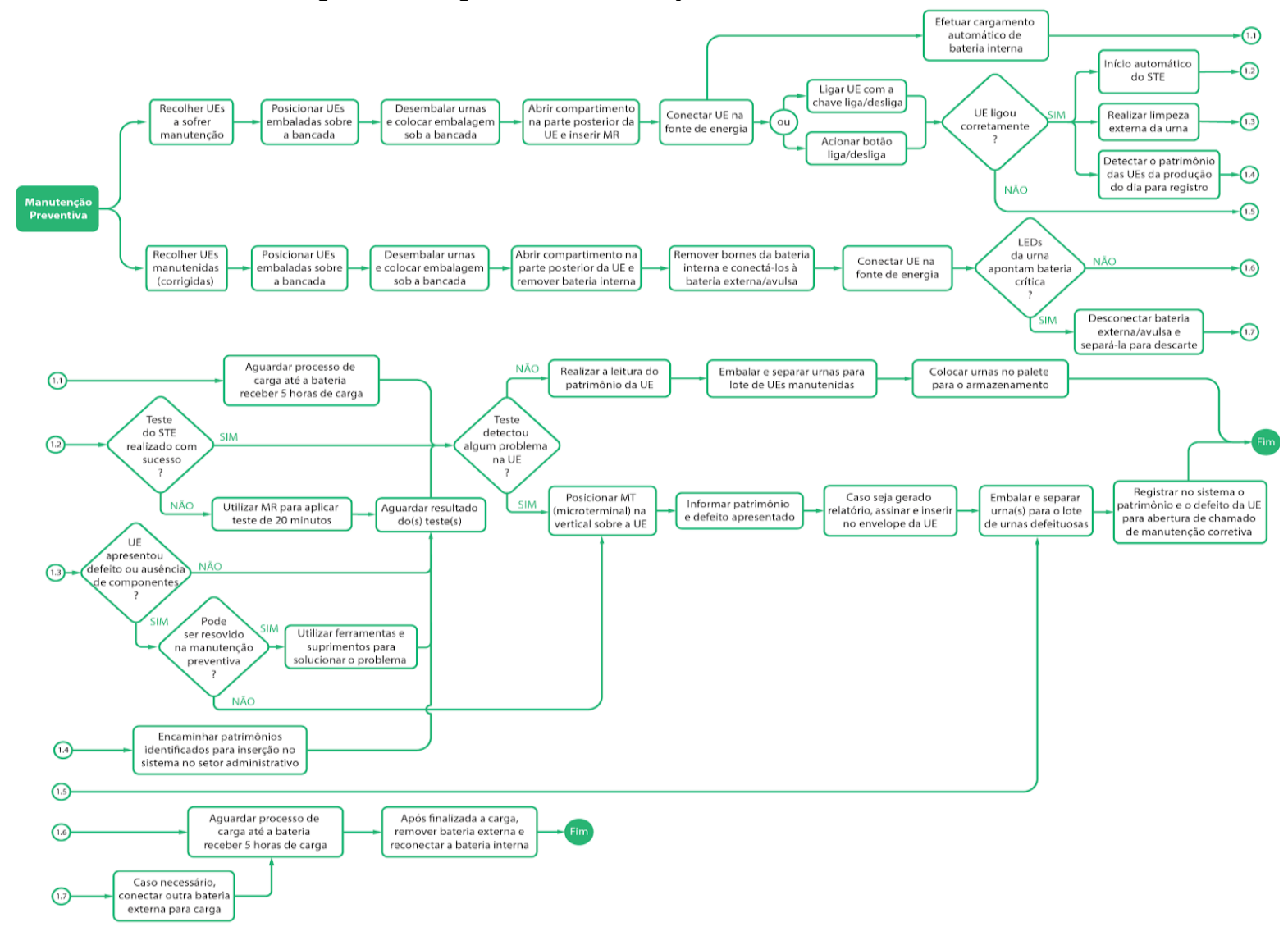




\section{$17^{\circ}$ ERGODESIGN \& USIHC 2019 \\ PUC-Rio, 11 a 13 de dezembro \\ Rio de Janeiro, RJ, Brasil}

$17^{\circ}$ Ergodesign - Congresso Internacional de Ergonomia e Usabilidade de Interfaces Humano Tecnológica: Produto, Informações Ambientes Construídos e Transporte

$17^{\circ}$ USIHC - Congresso Internacional de Ergonomia e Usabilidade de Interfaces Humano Computador

\subsection{Estratificação dos constrangimentos ergonômicos}

Após a compreensão do funcionamento da manutenção de UEs, foi possível estratificar os constrangimentos ergonômicos identificados, como descrito a seguir.

\subsubsection{Constrangimentos de ordem física}

Acerca da organização do espaço, observou-se que os pallets em frente às mesas (Figura 10) são uma fonte de risco por causarem desníveis na área de deslocamento, interferindo na passagem dos funcionários, podendo resultar em quedas. Dischinger, Ely e Piardi (2012) recomendam que o dimensionamento das circulações permita a continuidade das rotas, sem conter barreiras, e o piso deve oferecer boas condições de segurança e conforto. lida e Buarque (2016) recomendam que todos os obstáculos e desníveis nas rotas de caminho devem ser removidos, pois, pequenos desníveis de até $5 \mathrm{~cm}$ representam as maiores causas de quedas.

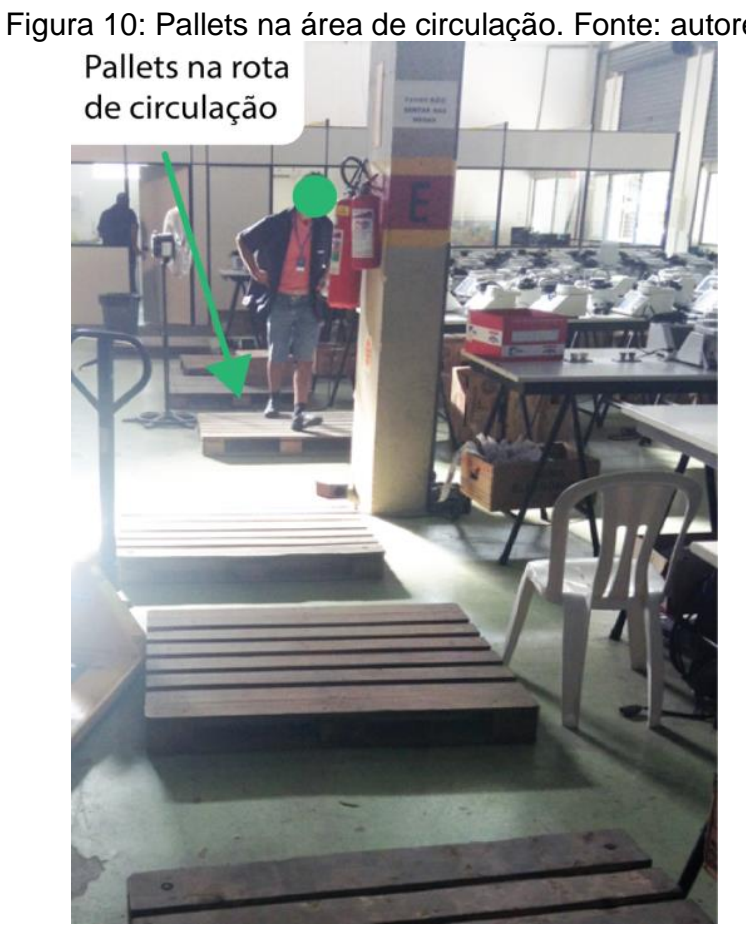

Há a constante flexão da região cervical e inclinação do tronco pelos funcionários durante a interação com a urna por ela não estar posicionada próxima a altura dos olhos (Figura 11), podendo trazer desconforto e riscos à saúde, além de impactar no desempenho do trabalho. Há ainda flexão do tronco para recuperação e colocação das embalagens das urnas nos pallets e sob as mesas.

Acerca da flexão do pescoço e tronco durante as atividades, percebe-se que em parte isso se deve ao mobiliário utilizado, pois como afirmam lida e Guimarães (2016), o ato de inclinar a cabeça em casos de pequenas montagens e inspeção de peças pode estar relacionado com uma estação de trabalho muito baixa, o que aumenta a carga sobre o dorso e o pescoço. Essa inclinação provoca a rápida fadiga dos músculos do pescoço e do ombro, e as dores começam 
$17^{\circ}$ ERGODESIGN \& USIHC 2019

PUC-Rio, 11 a 13 de dezembro

Rio de Janeiro, RJ, Brasil $17^{\circ}$ Ergodesign - Congresso Internacional de Ergonomia e Usabilidade de Interfaces Humano Tecnológica: Produto, Informações Ambientes Construídos e Transporte

$17^{\circ}$ USIHC - Congresso Internacional de Ergonomia e Usabilidade de Interfaces Humano Computador

a surgir quando a inclinação da cabeça em relação a vertical for maior que $30^{\circ}$.

Um ponto importante é que as dimensões de altura do posto de trabalho parecem estar configuradas para o trabalho sentado, mas as atividades são majoritariamente executadas em pé. Além disso, o tipo de trabalho executado é de precisão, que requer uma bancada ao invés de uma mesa, com superfície até $5 \mathrm{~cm}$ acima do cotovelo (IIDA; GUIMARÃES, 2016). Isso contribuiria para que os componentes das urnas como o teclado e o monitor ficassem mais próximos da linha de visão, reduzindo a inclinação do tronco e a flexão da cervical.

Figura 11: configurações do posto de trabalho e posturas adotadas. Fonte: autores.

Flexão de tronco e da região cervical durante a manutenção

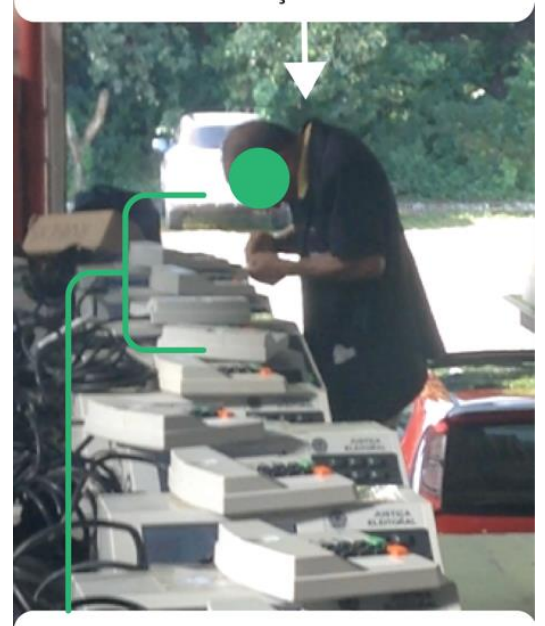

urnas abaixo da linha de visão, demandando a realização das flexões
Flexão de tronco para recuperação das embalagens de urnas
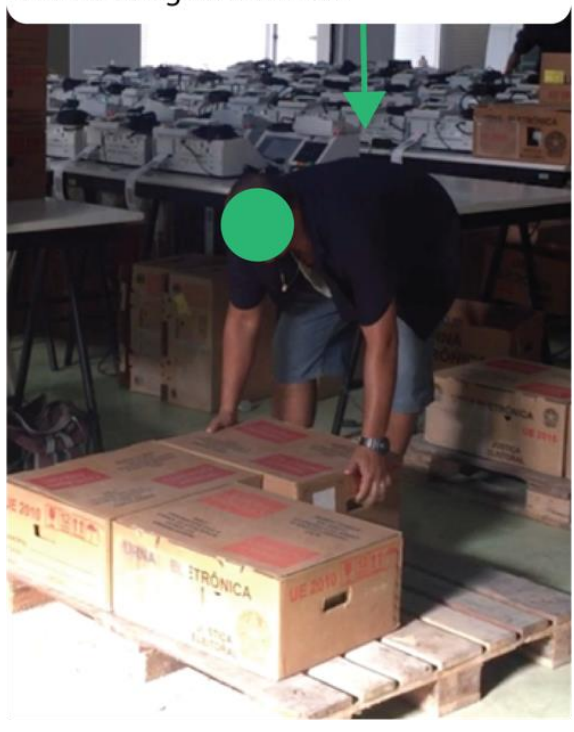

Acionamentos desfavoráveis devido ao poscionamento da urna

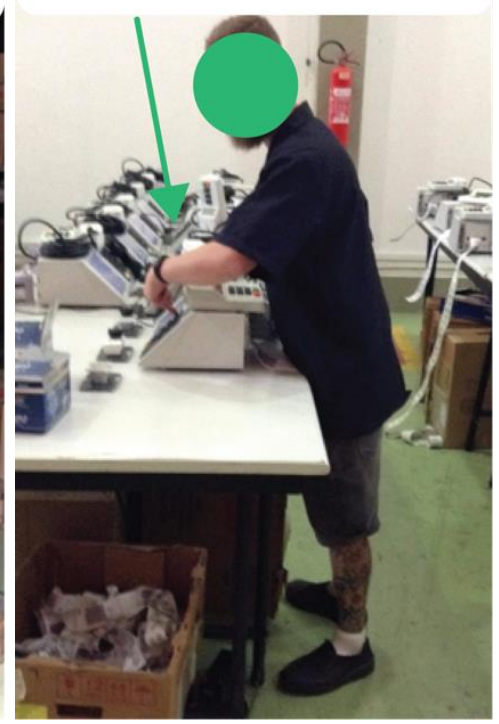

Sobre a flexão de tronco observada para recolhimento das embalagens, lida e Buarque (2016), recomendam que seja eliminado ao máximo possível as tarefas de levantamento de carga, sendo preferível que as cargas estejam no mesmo nível, para que não precisem ser abaixadas ou levantadas. Acerca das posturas adotadas quando houver movimentação, os autores recomendam que as cargas devem ser suportadas pelas musculaturas das pernas, evitando curvaturas ou torções da coluna vertebral.

As atividades envolvem esforços repetitivos, torção da musculatura do tronco e acionamentos desfavoráveis, em parte devido às posturas adotadas pelos funcionários, como nos casos em que a urnas é posicionada com o monitor na direção oposta ao trabalhador, fazendo com que seja necessário realizar a rotação do tronco e flexão do pescoço para visualizar a tela. Essas posturas podem causar fadiga muscular e lombalgia que, em casos mais graves, podem resultar na incapacitação temporária do trabalhador.

Essas condições, além de envolverem questões quanto ao projeto do local de trabalho, pois a restrição de espaço pode contribuir para o aumento de erros, também envolvem a conscientização dos funcionários acerca dos riscos a que estão expostos, pois prioriza-se o rendimento (mais urnas sobre a mesa, mais testes sendo realizados simultaneamente) sobre 0 conforto (IIDA; GUIMARÃES, 2016).

Verificou-se que os funcionários não utilizam equipamento de segurança, como luvas, para o contato direto com as urnas, tendo sido relatado pelos funcionários ocasiões de corte nos dedos durante o manuseio de componentes. Segundo NR 6 (ABNT, 2006), os ambientes de 
$17^{\circ}$ ERGODESIGN \& USIHC 2019

PUC-Rio, 11 a 13 de dezembro

Rio de Janeiro, RJ, Brasil $17^{\circ}$ Ergodesign - Congresso Internacional de Ergonomia e Usabilidade de Interfaces Humano Tecnológica: Produto, Informações Ambientes Construídos e Transporte

$17^{\circ}$ USIHC - Congresso Internacional de Ergonomia e Usabilidade de Interfaces Humano Computador

trabalho podem criar vários riscos para as mãos, seja de origem química, cortes ou queimaduras. Portanto, é importante avaliar o risco inerente a cada tarefa, e assim selecionar uma luva que exerça uma proteção especializada.

No ambiente de trabalho, percebe-se a presença de materiais, resíduos e componentes que não são necessários para as tarefas executadas e que interferem no desempenho das atividades. Além disso, os espaços destinados aos extintores de incêndio estavam obstruídos (Figura 12), com ventiladores e cadeiras invadindo a área de segurança.

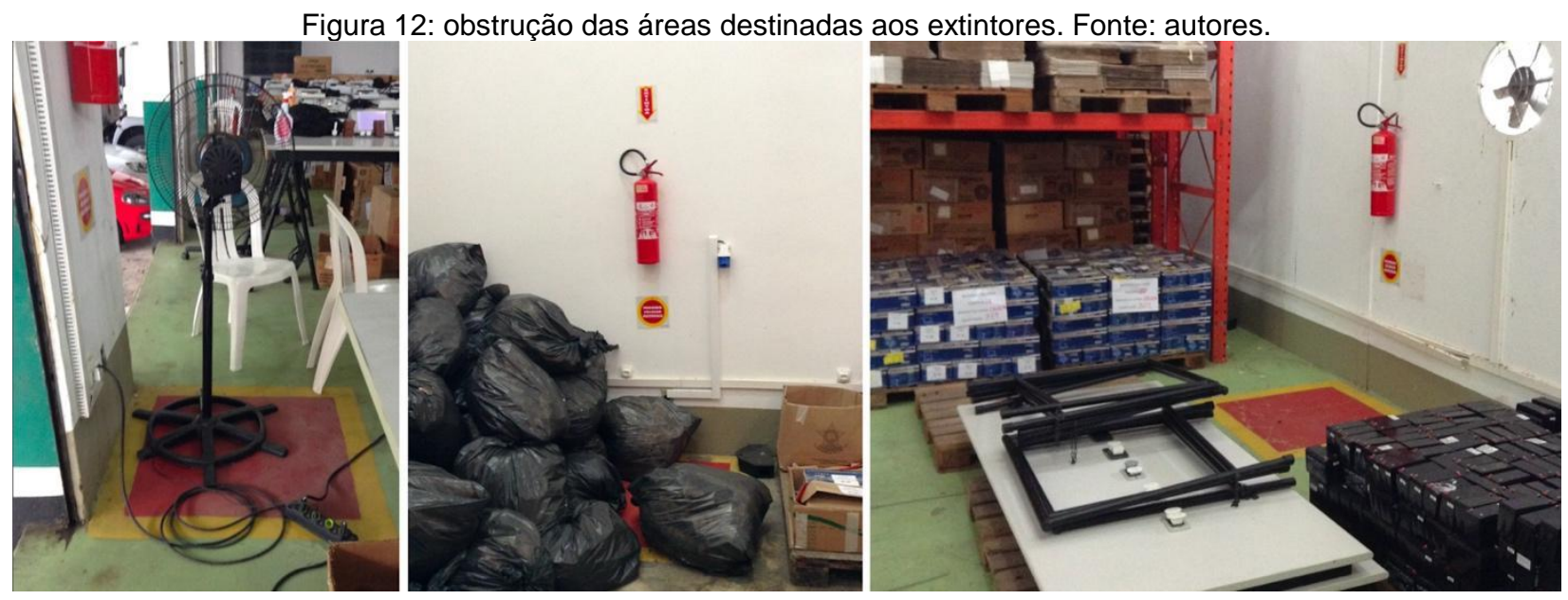

Quando chove, há o vazamento e acúmulo de água no piso perto dos cabos de alimentação energética das mesas e sobre a rota de locomoção dos técnicos (Figura 13). Esses vazamentos além de serem risco aos equipamentos, também são uma fonte de risco para os funcionários. De acordo com a NR 12 - Segurança no Trabalho em Máquinas e Equipamentos (ABNT, 2018), as instalações elétricas das máquinas e equipamentos que estejam ou possam estar em contato direto ou indireto com água ou agentes corrosivos devem ser projetadas com meios e dispositivos que garantam sua blindagem, estanqueidade, isolamento e aterramento, de modo a prevenir a ocorrência de acidentes.

Figura 13: acúmulo de água próximo às estações de trabalho. Fonte: autores.

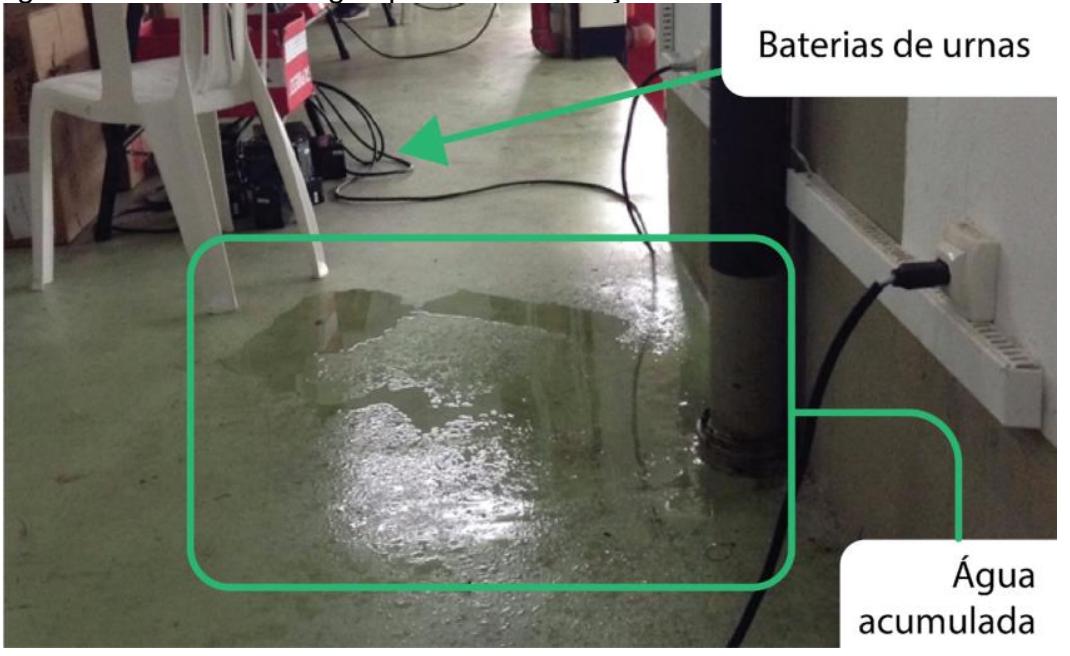


$17^{\circ}$ ERGODESIGN \& USIHC 2019

PUC-Rio, 11 a 13 de dezembro

Rio de Janeiro, RJ, Brasil $17^{\circ}$ Ergodesign - Congresso Internacional de Ergonomia e Usabilidade de Interfaces Humano Tecnológica: Produto, Informações Ambientes Construídos e Transporte

$17^{\circ}$ USIHC - Congresso Internacional de Ergonomia e Usabilidade de Interfaces Humano Computador

Notou-se a presença de fiação elétrica dispersa ao longo do local de trabalho, podendo interferir na circulação e ser um risco elétrico. Segundo NR 10 (ABNT, 2004), em instalações elétricas devem ser adotadas medidas preventivas de controle do risco elétrico e de outros riscos adicionais, mediante técnicas de análise de risco, de forma a garantir a segurança e a saúde no trabalho.

As mesas de manutenção e cadeiras para descanso ficam muito próximas das docas de carga e descarga do galpão, sendo uma fonte de risco por não haver nenhum tipo de proteção nas docas (Figura 14), podendo resultar em quedas. Segundo NR 18 (ABNT, 2011), é obrigatória a instalação de proteção coletiva onde houver risco de queda de trabalhadores ou de projeção de materiais. Aberturas, como no caso das docas, devem ser protegidas por guarda-corpo fixo por sistema de fechamento do tipo cancela ou similar.

Figura 14: docas do galpão. Fonte: autores.

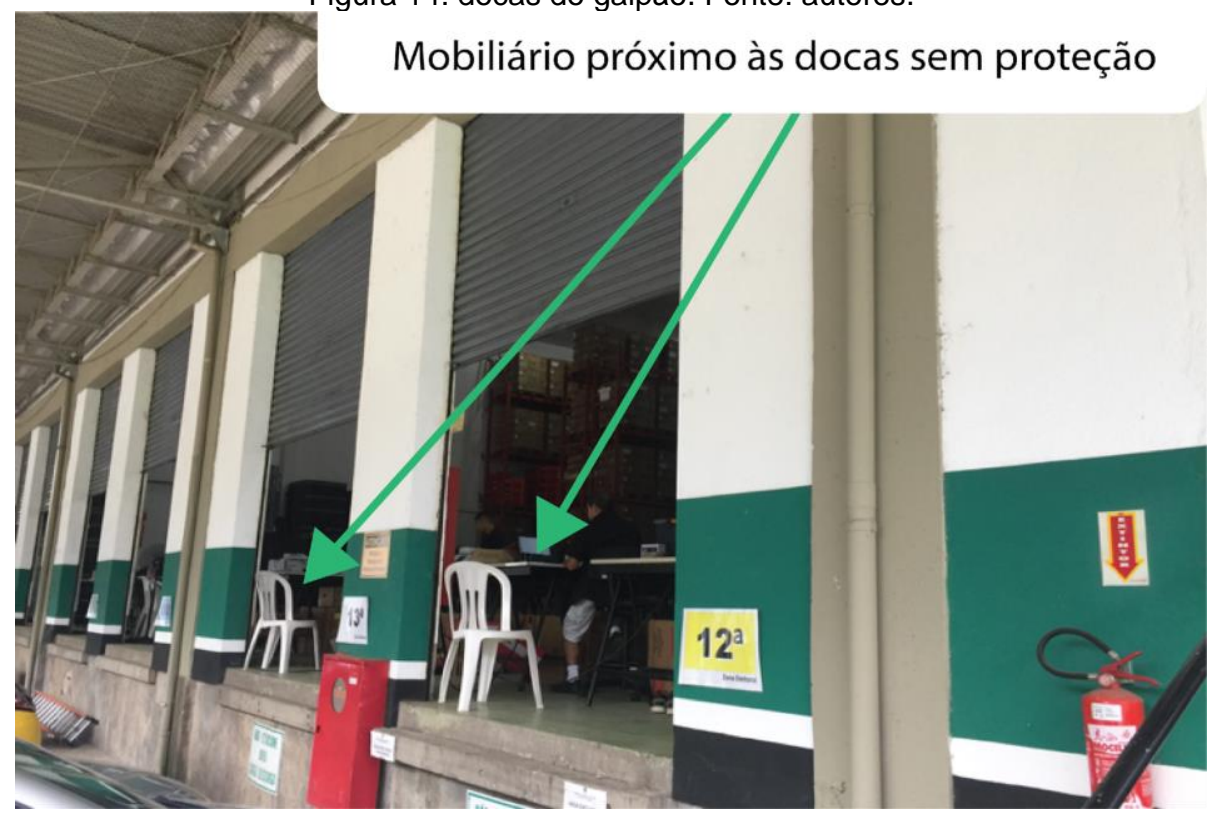

Durante o período vespertino, há o ofuscamento das informações apresentadas nos monitores das urnas pela luz natural advinda de aberturas próximas a cobertura do galpão e, ao longo do dia, há grande variação da luminosidade, o que interfere na percepção das informações.

Figura 15: variação da iluminação no ambiente. Fonte: autores.

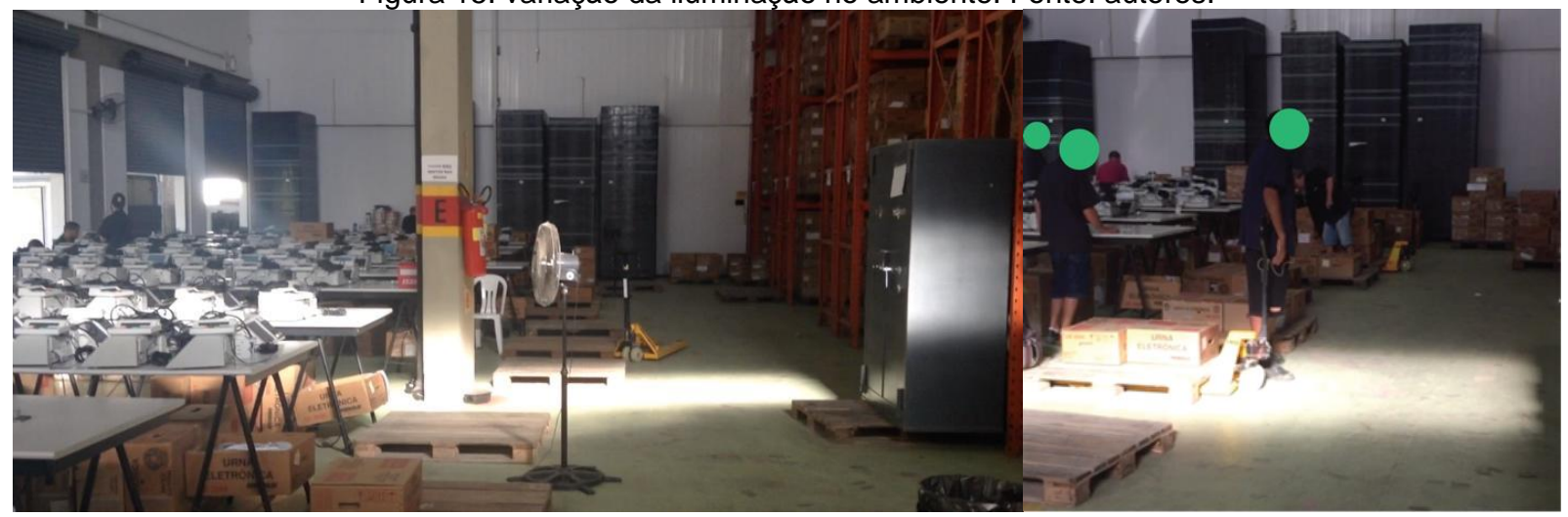




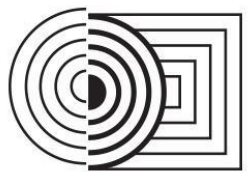

\section{$17^{\circ}$ ERGODESIGN \& USIHC 2019 \\ PUC-Rio, 11 a 13 de dezembro \\ Rio de Janeiro, RJ, Brasil}

$17^{\circ}$ Ergodesign - Congresso Internacional de Ergonomia e Usabilidade de Interfaces Humano Tecnológica: Produto, Informações Ambientes Construídos e Transporte

$17^{\circ}$ USIHC - Congresso Internacional de Ergonomia e Usabilidade de Interfaces Humano Computador

Um iluminamento deficiente sobre uma tarefa que exija precisão, como as atividades de reposição de pequenas peças e parafusos nas urnas, pode ser fatigante, ao passo que focos de luz brilhante no campo de visão podem provocar reflexos e ofuscamentos de grande desconforto. Desta forma, é preciso que a luz que incida sobre o posto de trabalho seja uniforme, bem como difusa ou indireta (IIDA; GUIMARÃES, 2016).

\subsubsection{Constrangimentos de ordem cognitiva}

Um dos pontos que apresentou mais reclamações durante as entrevistas foi o software de testes das urnas, que em sua versão mais estendida demanda horas para a conclusão, podendo apresentar erros e travamentos que exigem o reinício dos testes. Como afirmam Gonçalves e Quaresma (2015), a falibilidade de sistemas automatizados pode comprometer a interação de diferentes maneiras, afetando diversos estágios da interação Humano-Máquina, consequentemente levando a uma série de tipos de erros. No caso da manutenção, os técnicos utilizam-se de uma MR contendo uma versão com menor tempo de duração dos testes, de modo a não atrasar a linha de produção.

Como identificado nas observações e entrevistas, várias urnas solicitam a realização do teste do operador ao mesmo tempo, podendo resultar no aumento da frequência de erros e omissões na tomada de decisões (IIDA; BUARQUE, 2016). No TRE, foram relatados erros de associação dos modelos de urnas com as respectivas embalagens e a ocorrência de urnas defeituosas não serem detectadas.

\subsubsection{Constrangimentos de ordem organizacional}

Os funcionários não passam por treinamento formal, e o mapeamento representativo dos processos de manutenção não contém todas as atividades realizadas, propiciando o surgimento de lacunas de conhecimento sobre os procedimentos de manutenção. Segundo lida e Guimarães (2016), devem ser preparados materiais de instrução em linguagem compatível com o repertório dos usuários para serem usados em programas de treinamento e consultas durante as operações e manutenção.

O TRE analisado não conta com uma empilhadeira adequada para movimentação dos pallets de urnas, posicionadas nos níveis mais altos das estruturas de armazenagem, sendo necessário a solicitação da empilhadeira de terceiros para o transporte das urnas, podendo interferir no processo de manutenção preventiva.

Devido ao arranjo do ambiente/layout não favorecer as tarefas executadas, em vista da alocação inconveniente das estações de trabalho e do espaço reduzido, observa-se a quebra no fluxo de trabalho para deslocamento entre uma estação de trabalho e outra. Nesse sentido, a estação de trabalho deve ser dimensionada de acordo com o tamanho das peças a serem trabalhada, os movimentos necessários à tarefa e o arranjo do posto de trabalho (IIDA; BUARQUE, 2016).

\section{CONCLUSÃO}

Este estudo permitiu a compreensão das características e das principais variáveis envolvidas no processo de manutenção preventiva de UE (contingente, atores e ações realizadas), a partir da sistematização da manutenção.

As modelagens da sistematização contribuíram para a identificação das disfunções do sistema, 
o que permitiu que os constrangimentos ergonômicos fossem caracterizados quanto às ordens física, cognitiva e organizacional da Ergonomia, a partir do qual foi possível identificar o impacto desses constrangimentos na execução das atividades.

Os principais pontos que interferem no desempenho e se mostram fontes de risco ao trabalhador têm relação com o arranjo das estações de trabalho, sendo um ambiente inadequado ao processo de manutenção, além de se utilizar de um mobiliário desajustado às tarefas executadas, resultando em constantes constrangimentos ergonômicos para os funcionários (esforços repetitivos, flexão da região cervical, pescoço e tronco por exemplo). Além da necessidade de readequação das instalações físicas, é necessária a conscientização dos funcionários quanto às posturas e movimentações nocivas que precisam ser evitadas. Para trabalhos futuros, recomenda-se o aprofundamento nos aspectos organizacionais da gestão do fluxo de trabalho, da configuração do ambiente e dos processos produtivos, a fim de serem apontadas alternativas para minimizar os gargalos identificados. Recomenda-se ainda a expansão das análises dos aspectos cognitivos e das interações com as interfaces informatizadas do trabalho e do software de teste fornecido pelo TSE, apontado como uma fonte de insatisfação.

\section{REFERÊNCIAS BIBLIOGRÁFICAS}

ASSOCIAÇÃO BRASILEIRA DE NORMAS TÉCNICAS. NBR 6: equipamento de proteção individual - EPI. 2006.

NBR 9: programa de prevenção de riscos ambientais. 2017.

NBR 10: segurança em instalações e serviços em eletricidade. 2004.

NBR 12: segurança no trabalho em máquinas e equipamentos. 2018.

NBR 18: condições e meio ambiente de trabalho na indústria da construção. 2011.

DISCHINGER, Marta; ELY, Vera Helena Moro Bins; PIARDI, Sonia Maria Demeda Groisman.

Promovendo acessibilidade espacial nos edifícios públicos: Programa de Acessibilidade à Pessoas com Deficiência ou Mobilidade Reduzida nas Edificações de Uso Público. Florianópolis: Mpsc, 2012. 161 p.

DUL, Jan; WEERDMEESTER, Bernard. Ergonomia prática. 3. ed. São Paulo: Blucher, 2012. $163 p$.

GONÇALVES, R. C.; QUARESMA, M. Caracterização e Modelagem dos tipos de erro humano na interação com sistemas automatizados. in: ergodesign \& usihc, 15., 2015, Recife. Anais... São Paulo: Blucher, 2015. v. 2, p. 1222 - 1233.

HERMANN, Walter; BOVO, Viviani. Mapas mentais: enriquecendo inteligências. 2. ed. Campinas: Walter Hermann; Viviani Bovo, 2005.

IIDA, Itiro.; GUIMARÃES, Lia Buarque de Macedo. Ergonomia: projeto e produção. 3. ed. São Paulo: Blucher, 2016.

JUSTIÇA ELEITORAL. Manual de Exercitação de Urnas Eletrônicas - modelos: UE2004, UE2006, UE2008, UE2009, UE2010, UE2011. 1a. Edição. Brasília: Tribunal Superior Eleitoral, 2012.

PRODANOV, Cleber Cristiano; FREITAS, Ernani Cesar de. Metodologia do trabalho científico: métodos e técnicas da pesquisa e do trabalho acadêmico. 2. ed. Novo Hamburgo: Feevale, 2013. 277 p.

PAZMINO, Ana Veronica. Como se cria: 40 métodos para design de produtos. São Paulo: Blucher, 2015.

TRIBUNAL SUPERIOR ELEITORAL. Justiça eleitoral divulga balanço de ocorrências nas 


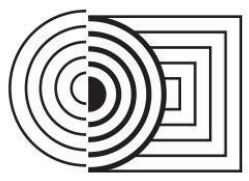

\section{$17^{\circ}$ ERGODESIGN \& USIHC 2019 \\ PUC-Rio, 11 a 13 de dezembro \\ Rio de Janeiro, RJ, Brasil}

$17^{\circ}$ Ergodesign - Congresso Internacional de Ergonomia e Usabilidade de Interfaces Humano Tecnológica: Produto, Informações Ambientes Construídos e Transporte

$17^{\circ}$ USIHC - Congresso Internacional de Ergonomia e Usabilidade

de Interfaces Humano Computador

Eleições 2018. 2018b. Disponível em: <http://www.tse.jus.br/imprensa/noticiastse/2018/Outubro/justica-eleitoral-divulga-balanco-de-ocorrencias-nas-eleicoes-2018>. Acesso em: 09 set. 2019.

- Nota de esclarecimento: Empresa Smartmatic e urnas eletrônicas brasileiras. 2017. Disponível em: <http://www.tse.jus.br/imprensa/noticias-tse/2017/Agosto/nota-deesclarecimento-empresa-smartmatic-e-urnas-eletronicas-brasileiras>. Acesso em: 09 set. 2019.

O TSE: o Tribunal. Brasília, Tribunal Superior Eleitoral, 2019. Disponível em: <http://www.tse.jus.br/o-tse/sobre-o-tse/apresentacao>. Acesso em: 04 set. 2019.

Por dentro da urna. 2. Ed., rev. e atual. Brasília: Tribunal Superior Eleitoral, 2010.

TSE conclui licitação para manutenção de urnas eletrônicas. 2012. Disponível em:

$<$ https://tse.jusbrasil.com.br/noticias/3183632/tse-conclui-licitacao-para-manutencao-de-urnas-

eletronicas>. Acesso em: 09 set. 2019.

Urna eletrônica: 20 anos a favor da democracia. 2016. Disponível em: <http://www.justicaeleitoral.jus.br/arquivos/tse-urna-eletronica-20-anos-a-favor-da-democracia>. Acesso em: 09 set. 2019.

Urna eletrônica usa tecnologia desenvolvida por técnicos do próprio TSE. 2018a. Disponível em: <http://www.tse.jus.br/imprensa/noticias-tse/2018/Setembro/urna-eletronica-usatecnologia-desenvolvida-por-tecnicos-do-proprio-tse>. Acesso em: 09 set. 2019.

\section{AGRADECIMENTOS}

O presente trabalho foi realizado com apoio da Coordenação de Aperfeiçoamento de Pessoal de Nível Superior - Brasil (CAPES) - Código de Financiamento 001.

Agradecemos ao Programa de Pós-graduação em Design da UFSC (PPGD/UFSC), ao Núcleo de Gestão de Design e Laboratório de Design e Usabilidade (NGD-LDU/UFSC), e à Marcos Lucas. 